\title{
生态治理政策工具对农户行为的影响差异研究
}

以宁夏盐池县为例

\author{
夏翠珍 ${ }^{1,2}$, 周立华 ${ }^{1,3, *}$, 廖 杰 $^{4}$, 王 娅 $^{4}$, 刘 慧 ${ }^{2,5}$ \\ 1 中国科学院科技战略咨询研究院, 北京 100190 \\ 2 中国科学院大学, 北京 100049 \\ 3 中国科学院大学公共政策与管理学院,北京 100049 \\ 4 中国科学院西北生态环境资源研究院, 兰州 730000 \\ 5 中国科学院地质与地球物理研究所, 北京 100029
}

摘要:政策工具被认为是政府为解决某个公共问题采取的具体手段或措施,一项政策可以视作目标和多种政策工具的组合。在 生态治理过程中,不同政策工具对农户行为的刺激程度不同,进而导致不同的政策效果。分离不同政策工具的影响,可为工具 选择和政策优化提供科学参考。以盐池县为例,利用基于该县 1983-2017 年内出台的 316 份生态政策文本构建的政策工具数 据集和 VAR 模型中的脉冲响应和方差分解方法定量研究了强制型、混合型和自愿型三大类政策工具及十种子工具对农户耕 作、放牧、造林 3 种行为的影响。结果表明: (1) 政策工具对农户行为的影响具有时效性,一般在政策出台后 $2-3$ 年内影响最 大, 随后逐渐减小并消失, 影响持续时间为 7-10 年。(2) 总体来看, 政策工具对农户行为的冲击力度较小, 冲击范围在 0 - 0.30 之间, 说明农户行为还受到其他诸多因素的影响。(3) 10 年累计影响从大到小依次为强制型、混合型、自愿型,其中直接提供和 规制两种子工具的影响最大。放牧行为受到政策工具的刺激最大,耕作行为次之,造林行为最小。(4) 直接提供工具对耕作行 为具有最大正向影响, 最大冲击为 0.30 ; 规制工具在短期内抑制牲畜数量增长, 而直接提供和补贴工具促进牲畜数量增长, 且由 于冲击曲线存在正负波动, 说明政府与农户在牲畜养殖上存在长期博弯; 只有规制工具对造林行为具有积极影响, 说明造林更 多是在政府的主导下进行。建议充分利用政策工具的短期效应, 凸显政府角色,及时做好政策效果评估工作,调整工具组合,助 力生态目标的实现。

关键词: 政策工具; 农户行为; VAR 模型;盐池县

\section{Different effects of policy instruments of ecological governance on farmers' behaviors: A case study of Yanchi County, Ningxia}

\author{
XIA Cuizhen ${ }^{1,2}$,ZHOU Lihua ${ }^{1,3, *}$,LIAO Jie ${ }^{4}$, WANG Ya ${ }^{4}$, LIU Hui ${ }^{2,5}$ \\ 1 Institutes of Science and Development, Chinese Academy of Sciences, Beijing 100190, China \\ 2 University of Chinese Academy of Sciences, Beijing 100049, China \\ 3 School of Public Policy and Management, University of Chinese Academy of Sciences, Beijing 100049, China \\ 4 Northwest Institute of Eco-Environment and Resources, Chinese Academy of Sciences, Lanzhou 730000, China \\ 5 Institute of Geology and Geophysics, Chinese Academy of Sciences, Beijing 100029, China
}

\begin{abstract}
Policy instruments are considered to be specific means or measures taken by the government to solve public problems, and one policy can be regarded as the combination of objectives and various policy instruments. In the process of
\end{abstract}

基金项目: 国家重点研发计划项目 (2016YFC0500909); 国家重点研发计划项目 (2018YFA0606402)

收稿日期:2020-10-12; 网络出版日期:2021-07-24

* 通讯作者 Corresponding author.E-mail: lhzhou@ casisd.cn 
ecological governance, the degrees of policy instruments' stimulation to the behavior of local farmers are different, which further leads to different policy effects. The understanding of the influence of different policy instruments can provide a scientific reference for instrument selection and policy optimization. Taking Yanchi County as an example, using the data set of policy instruments constructed from 316 ecological policies issued by Yanchi County from 1983 to 2017 and based on the impulse response and variance decomposition method of VAR model, this paper quantitatively studies the impacts of various policy instruments that include mandatory instrument, hybrid instrument, voluntary instrument and ten sub-instruments on farmers' behaviors of farming, grazing, and afforestation. The results show that: (1) the impact of policy instruments on farmers' behaviors is time-sensitive, which would reach the maximum within 2 to 3 years after the instrument was implemented, and then gradually dwindle and disappear within 7 to 10 years. (2) Generally speaking, the impact of policy instruments on farmers' behaviors is relatively small, with an impulse response ranging from 0 to 0.30 , indicating that the farmers' behaviors are also affected by many other factors. (3) The 10 years cumulative impact is in descending order of the mandatory instrument, hybrid instrument and voluntary instrument; The two instruments, direct provision and regulation, have the greatest effects. Farmers' behavior of grazing is most stimulated by policy instruments, followed by farming and afforestation. (4) The instrument of direct provision has the greatest positive impact on farming behavior, with a maximum impact of 0.30 ; the instrument of regulatory may inhibit the growth of livestock numbers in the short term, while the instruments of direct provision and subsidy may promote the growth of livestock numbers. There are fluctuations between positive and negative in the impulse response curves, indicating that there has been a long-term game between the government and farmers in livestock breeding. Only the instrument of regulatory has a positive impact on the behavior of afforestation, which indicates that afforestation is more under the leadership of the government. To realize the goal of ecological protection, it is recommended to make full use of the short-term effects of policy instruments, highlight the role of the government, and optimize the combination of instruments.

Key Words : policy instrument; farmers' behavior; VAR model; Yanchi County

十八大以来,中央政府提出要推进国家治理体系与治理能力现代化,特别强调生态环境保护制度的创新。 如何判断政策措施的优劣,有针对性地实施政策,提高政策绩效,受到诸多学者关注 ${ }^{[1-2]}$ 。政策工具,一般认 为是政府为解决某个公共问题采取的具体手段或措施 ${ }^{[2-3]}$, 是目前公共管理领域的研究热点。政策工具研究 兴起于 19 世纪 80 年代西方从“政府管理”转向“政府治理”的新公共管理改革运动,学者们意识到工具知识 的缺乏和不足是政策失败的原因,因此考虑将政策研究和公共管理的分析单元聚焦到公共项目所使用的基础 操作工具上 ${ }^{[4]}$ 。经基尔申、萨拉蒙、胡德、陈振明等国内外学者发展后,目前已被广泛运用到财政、金融、环保

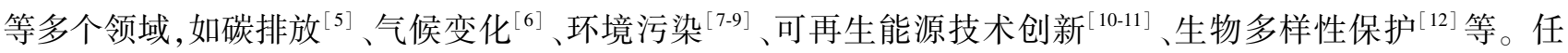
何一项政策都可以视为政策目标与政策工具的有机统一 ${ }^{[13-15]}$, 一项政策可以由多种政策工具构成,一种工具 也可以在多项政策中使用。生态治理政策是以生态治理为目标,融合多种手段和方法的工具组合。政策发挥 的效果, 可以视为多种政策工具的综合作用 ${ }^{[16]}$ 。

中国北方农牧交错区生态环境恶劣脆弱,在生态恢复问题上,政府扮演主导角色,农户是政策的被动接受 者,从政策工具执行到发挥作用的过程中,农户对工具的响应及行动是其中的重要一环。研究农户对政策工 具的响应,探究不同工具之间的差异, 对优化工具选择和提升政府管理效能具有重要意义。为实现生态目标, 政府采用的工具比较多样化,政府既要加强管制 (如禁垦、禁伐、禁牧)，也要利用市场机制 (发展沙产业), 同 时做好宣传工作 (鼓励植树种草) 等。在以往有关政策对农户行为影响的研究中,考虑单一政策或工具影响 的研究很多, 如退耕还林工程 ${ }^{[17]}$ 、草原生态补奖政策 ${ }^{[18]}$ 、禁牧政策 ${ }^{[19]}$ 等, 研究方法多以政策为背景, 以政策 实施前后相应指标的变化来突出政策的作用 ${ }^{[20]}$, 但缺乏对政策的工具属性及其影响差异的研究。目前, 在生 态治理上,已经有学者开始探索不同政策工具的应用,比如冀光楠等人分析了天保工程区集体林管理中运用 的政策工具 ${ }^{[21]}$, 黄明分析了行政、经济和物理三类政策工具对农户低碳能源使用行为的影响 ${ }^{[22]}$, 黄金梓提议 在生态扶贫中运用多元政策工具 ${ }^{[23]}$ 等。在如何选择政策工具上, 学者们也做了一些探索, 比如童洪志运用二 
元选择 logit 模型发现监管约束与惩罚、补贴、信息诱导 3 种政策工具对农户采纳秸秆还田技术具有积极作 用 ${ }^{[24]}$ 。但目前对北方农牧交错区的生态治理政策工具及其对农户行为影响的研究还很少见。

为了定量研究农户行为对不同政策工具的响应,本文借鉴了 VAR(向量自回归模型) 模型。该模型 19 世 纪 80 年代由西蒙提出,最早被用于探究宏观经济系统中各变量之间的相互作用关系,该模型可以基于时间序 列变量的信息模拟出自变量与因变量之间可能存在的同期或者滞后的相关关系。目前,在环保领域,主要是 环境污染领域,已经有不少学者运用 VAR 模型对环境政策工具的生态、经济作用做了计量分析,如张可等运 用对比分组的 VAR 模型分析了水环境政策对农业增长与面源污染的影响 ${ }^{[25]}$; 张卫东等分析了环境政策对经 济增长和环境污染总体关系的影响 ${ }^{[26]}$; 黄清子利用 GRA-VAR 模型研究了三类六项政策工具对环保产业的 促进作用,发现科技政策最优、法制政策工具最弱 ${ }^{[27]}$ 。但是在生态治理领域,对政策工具的对比分析还几乎 没有。本文以盐池县为典型区,在辨析盐池县所采用政策工具的基础上,结合已获取的 1983-2017 年盐池县 生态治理政策所采用的政策工具数据集,运用 VAR 模型中的脉冲响应和方差分解函数研究农户对各种政策 工具的响应,探究政策工具对农户行为的影响差异,判断哪种政策工具对农户行为的调节力度最大, 为后续的 政策工具选择和管理优化提供参考, 具有一定的现实意义。

\section{1 盐池县概况}

盐池县位于宁夏回族自治区东部( 图 1), 该区干旱少雨, 风大沙多,年平均降水量 $294.6 \mathrm{~mm}$, 蒸发量 2897 $\mathrm{mm}$ 。盐池县是农牧交错带上最为典型的气候、地形、土壤、植被、资源利用多重复合过渡地带, 相比于其它区 域, 盐池县对于环境扰动的反应更加迅速且具有放大作用 ${ }^{[28]}$ 。作为全国 266 个牧区县之一, 盐池县草原面积 辽阔。根据中国荒漠化 (土地退化) 防治研究课题组的分析,过去盐池县环境破坏的原因主要有过度开剭、过 度放牧、过度樵采等 ${ }^{[29]}$ 。经过大力治理, 如今, 盐池县的沙漠化面积大幅缩减, 众多学者都认为其中起决定性 作用的是退耕还林还草、草地禁牧、禁止乱砍乱挖和植树造林等政策措施 ${ }^{[30]}$ 。

\section{2 政策工具-农户行为-生态治理的关系}

可供政府选择的政策工具十分丰富,学者们提出多种分类方式,在不同研究领域采用的分类方法有所不 同 ${ }^{[20]}$ 。经过实践,越来越多学者倾向于将政策工具分为命令控制、经济刺激和自愿行动 3 种类型 ${ }^{[31-33]}$ 。为了 更好地区分基层政府所使用的政策工具, 此次研究采用迈克尔 - 霍利特和拉米什等人的分类框架 ${ }^{[34]}$, 按照强 制型程度, 以完全自愿和完全强制为两端, 将各项政策工具依次排列, 总体可分为强制型、混合型和自愿型 3 大类以及 10 小类工具。自改革开放以来,中国在生态治理上加大资金和人力投人,自上而下实施了三北防护 林、退牧还草等重大生态工程,这些工程都通过具体政策文件得到贯彻落实。政策可以视作政策目标和政策 工具的组合, 如禁牧政策可以视为以禁绝放牧为目标, 直接提供、规制、税收和使用费、补贴和奖励、使用权、信 息与劝解、家庭与社区等工具的组合。图 2 描述了在生态治理过程中,政府通过政策工具调控农户行为进而 达到生态可持续恢复的逻辑关系图。

生态治理政策的作用对象主要是农户,作为理性经济人,农户将在自身利益和违规风险之间做权衡。政 策下达后,农户将根据自身的资源禀赋情况做出最有利于自己的选择,而农户的行为调整方向,直接影响到生 态治理效果。生态治理目标的达成就是农户在各项政策工具的综合影响下采取行动后产生的累计效应。不 同资源禀赋的农户受政策影响不同, 调整方式也多种多样, 比如减少牲畜、退耕还林、发展副业等。因此, 考虑 到农户行为的复杂性, 从生态治理目标和人地关系角度, 将农户社会经济活动视为一个自主运行的系统, 将政 策工具作为一项外部影响因素, 主要探究可观测的对生态环境有重大影响的行为会对政策工具产生什么样的 响应。在以往研究中, 过度放牧、滥层滥伐、过度樵采等被视为盐池县沙漠化的主要原因, 因此, 选择农户耕 作、放牧和造林行为作为代表变量。 


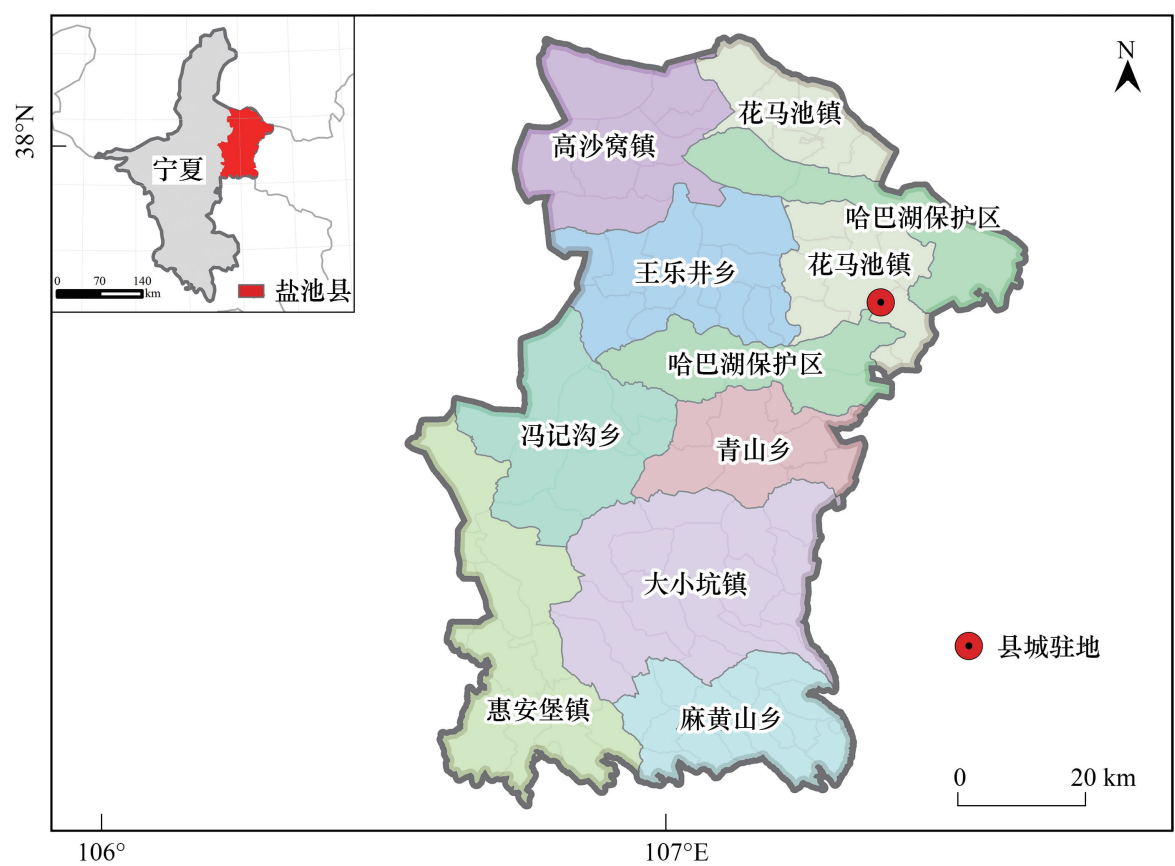

图 1 盐池县区位图

Fig.1 Location of Yanchi County

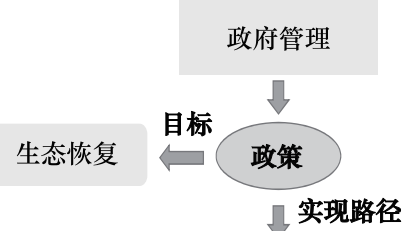

规制: 严格禁止对生态产生破坏 的行为, 如禁牧、禁挖甘草 直接提供: 为当地农牧草林业发 展提供人力、资金和技术支持 国有企业: 控制农牧产品交易, 规范当地市场容量, 如控制出栏 量

信息与劝诫: 做好宣传工作, 引 导群众按照政策希望的方向行事 补贴与奖励: 弥补农户因生态政 策产生的损失, 奖励生态保护行 为

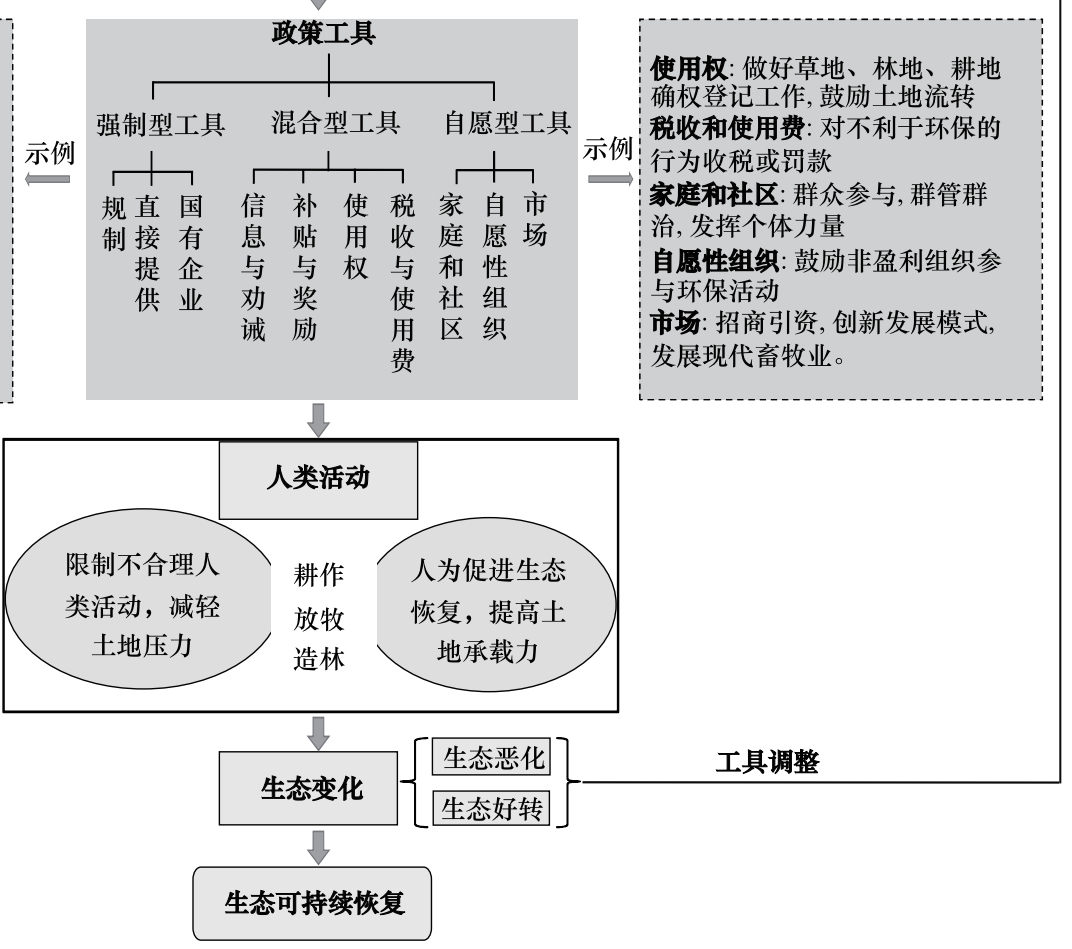

图 2 政策工具-农户行为-生态恢复的关系图

Fig.2 Diagram of relation among policy instrument, farmers' behavior and ecological restoration 


\section{3 数据来源与方法}

\section{1 变量选取与数据来源}

\subsection{1 农户行为变量}

针对当地的问题以及数据的可得性,在县域层面上,本文选择农户人均播种面积、人均牲畜数量、人均造 林面积作为耕作、放牧和造林行为的指标。选择播种面积而非耕作面积是因为土地产权固定，官方统计的耕 地面积变化很小,但是农户实际的播种面积却会随着外界自然和社会环境的变化发生变化。牲畜数量一定程 度上反映土地的承载压力。各种类牲畜按羊单位换算, 1 头牛 $=5$ 只羊, 1 匹马 $=4$ 只羊, 1 头驴/骡 $=3$ 只羊。 人均造林面积代表生态保护行为,在盐池县,大规模造林活动虽然由政府主导,但农户是实际执行者。以上数 据来自《盐池县经济要情手册 2016》、《盐池县统计年鉴》、《盐池年鉴》、《盐池县志》。

\subsection{2 政策工具变量}

以调控农户生产生活为目的的政策很多,这里重点关注农、牧、草、林类及防沙治沙、水土保持等与生态治 理息息相关的政策。一个政策文本可以分解出多种政策工具,政策工具的使用频次一方面可以反映政府的工 具偏好; 另一方面,以生态治理为目的,各项工具的方向相对一致,使用频次可以反映出政府在某个方向的执 行力度。因此,基于以上分析和数据可得性,为了探究不同政策工具对农户行为的影响以及各工具之间的使 用效果差异,将盐池县历年出台生态治理政策中使用的政策工具使用频次作为政策工具的指标。在选择政策 工具变量时,有几个基本假设:一是政府具有工具惯性,即政府习惯性使用某些工具; 二是如果一种工具的效 果明显,那么政府会保持或者增加该工具的使用频率;三是政府会根据生态环境状况和上级规划调整当年的 发文数量, 导致政策数量和相应工具的使用频次在不同年份存在差异。

研究小组从 2017 年起多次前往盐池县进行数据的 收集工作,在盐池县农牧局、环林局、科技局、档案局等 处获取 1983-2017 年的生态政策文本, 由于资料从系 统的政府办全宗得到, 因此认为资料全面,可信度高。 在前期工作中, 课题组运用内容分析法, 对从政策库中 挑选出的 316 份政策文本进行编码统计,首先统计每一 份文件中使用过的工具, 然后按年份求和, 获得了各项 政策工具历年使用频次的时间序列数据集,详细步骤见 另一篇论文 ${ }^{[35]}$ 。由于自愿性组织工具仅有一次,因此 不考虑该项工具。所有变量如表 1 所示。每种工具的 定义参考迈克尔的原始定义及盐池的实情, 实例均来自 于盐池县曾出台的政策。各类工具的定义见表 2 。

\section{2 模型选取与构建}

\subsubsection{VAR 模型原理}

VAR (Vector autoregression) 模型是从数据的统计 性质出发,把系统中每一个内生变量作为系统中所有内 生变量的滞后值的函数来构造模型, 从而把单变量自回归模型推广到由多元时间序列变量组成的 “向量” 自 回归模型 ${ }^{[36]}$ 。以常数 $c$ 作为唯一外生变量,拥有滞后期 $p$ 的 VAR 模型的一般表现形式如下:

$$
\begin{gathered}
Y_{t}=\prod_{1} Y_{t-1}+\prod_{2} Y_{t-2}+\cdots+\prod_{p} Y_{t-p}+c+\varepsilon_{t}, \\
t=1, \cdots, T
\end{gathered}
$$

式中, $Y_{t}=\left(y_{1 t}, y_{2 t}, \cdots y_{n t}\right)^{\prime}$ 表示 $(n \times 1)$ 维时间序列向量, $\prod_{i}$ 是 $(n \times n)$ 维系数矩阵, $\varepsilon_{t}$ 是 $(n \times 1)$ 维不可见的 零均值白噪声矢量过程。理论经济学家在 VAR 模型基础上发展了脉冲响应函数和方差分解。脉冲响应函数 
反映的是当 VAR 模型中某一变量的误差项发生一个单位变化时 (脉冲) 给其他内生变量所带来的影响; 方差 分解结果是通过改写 VAR 模型得出的一个脉冲冲击对某一变量产生的多期累计冲击, 反映各个扰动项的相 对重要性。以两个变量 $y_{1}$ 和 $y_{2}$ 滞后两期为例, 所建立的 VAR 模型方程组为:

$$
\begin{aligned}
& y_{1 t}=a_{11} y_{1 t-1}+b_{11} y_{2 t-1}+a_{12} y_{1 t-2}+b_{12} y_{2 t-2}+c_{1}+\varepsilon_{1 t}, t=1, \cdots, T \\
& y_{2 t}=a_{21} y_{1 t-1}+b_{21} y_{2 t-1}+a_{22} y_{1 t-2}+b_{22} y_{2 t-2}+c_{2}+\varepsilon_{2 t}, t=1, \cdots, T
\end{aligned}
$$

表 2 政策工具定义与实例

\begin{tabular}{|c|c|c|c|c|}
\hline 类型 & 名称 & 定义 & 实例 & 来源 \\
\hline Type & Name & Definition & Example & Source \\
\hline \multirow[t]{2}{*}{$\begin{array}{l}\text { 强制型政策工具 } \\
\text { Mandatory instrument }\end{array}$} & 规制 & $\begin{array}{l}\text { 政府命令个人或团体遵 } \\
\text { 守某项规定或执行某项 } \\
\text { 决策,如果违背通常会受 } \\
\text { 到惩罚 }\end{array}$ & $\begin{array}{l}\text { 逐户清理核实饲养量, 逐户落实出栏销售任 } \\
\text { 务。凡不积极出售完不成出栏任务的农户, } \\
\text { 每超养一只羊征收草原费 } 20 \text { 元, 或集体终 } \\
\text { 止包干合同, 收回承包羊只 }\end{array}$ & $\begin{array}{l}1990 \text { 《关于认真做好秋 } \\
\text { 季羊只出栏工作的通 } \\
\text { 知》 }\end{array}$ \\
\hline & 直接提供 & $\begin{array}{l}\text { 政府直接履行职能, 向社 } \\
\text { 会提供物品与服务, 不依 } \\
\text { 靠其他对象提供 }\end{array}$ & $\begin{array}{l}\text { 开发实用技术参与灾害防御,开展多种形式 } \\
\text { 服务。经区人民政府批准, 每年 } 5-7 \text { 月在 } \\
\text { 我区开展人工增雨工作 }\end{array}$ & $\begin{array}{l}1990 \text { 《转发县气象站< } \\
\text { 关于气象科技兴农工 } \\
\text { 作报告>的通知》 }\end{array}$ \\
\hline
\end{tabular}

Table 2 Definition of policy instruments and examples

政府通过自己控制的企县食品公司和牧工商公司要把羊只出栏销 国有企业业或类似机构 (如供销社 等) 进行与市场有关的活 动, 调节市场需求

混合型政策工具 Hybrid instrument

信息与劝诫

政府给出参考的意见,引 导或劝诫公众按照政府 意愿调整他们的行为

政府使用荣誉、经济激励

补贴和奖励一等方式鼓励目标对象采 取有利于政策目标实现 的行动

政府在没有市场的领域， 使用权将稀缺资源的使用权固 定到具体对象,创造一个 可交易市场

政府通过对不受欢迎的 税收与使用费行为进行收费达到减少 该类行为的目的

自愿型政策工具 Voluntary instrument

家庭和社区

政府不参与,依靠家庭或 社区的自愿行动来进行 与生态治理相关的活动

政府依靠自由市场,通过 市场 市场规律调节相关的 活动

政府通过不由政府强制 成立, 仅出于自身利益、 自愿性组织道德和情感上的满足, 不 以盈利为目的组织进行 生态治理活动
县食品公司和牧工商公司要把羊只出栏销
售工作作为长年性任务, 与乡村和农户建立 销售关系和合同,牧商结合,四季购销

要采取各种会议、各种形式, 利用黑板报、宣 传专栏, 广播、图片、办学习班以及利用当前 农村扫盲的机会大张旗鼓地宣传国家颁布 森林法的重大意义

在查获毁坏林木、非法贩运木材、非法侵占 林地等涉林案件中, 对能够提供有价值线索 的有功人员给予奖励

以市场为导向, 以优化配置土地资源为目 标, 采取多种形式实现农村土地承包经营权 流转,包括转包、转让、互换、人股、反租倒 包、退包、租赁、抵押等多种流转形式

凡是采挖甘草的, 要逐步实行收费管理, 收 购和经营部门, 每收购一公斤甘草要向县草 原管理站上缴 0.05 元的草原建设费

把草原的管、建、用, 尤其是甘草资源的保护 工作, 要交给群众讨论, 拿出自己的意见和 办法

以优惠政策吸引社会资金, 招商引资吸引能 人、大户投资特色种养业开发, 激活民间资 本, 逐步形成以农民等经营者自主投人为 主, 以财政和项目扶持为补充, 社会各方积 极参与的投资机制, 促进农业产业快速发展

为了学习种树种草经验与先进管理办法, 开 阔乡、村、队干部的眼界, 同意你乡组织三十 五名乡、村队干部到榆林、延安两地区学习
1990 《关于认真做好秋 季羊只出栏工作的通 知》

1984《关于宣传贯彻 < 中华人民共和国森林 法 $>$ 的通知 $\rangle$

2006《关于印发<盐池 县林地保护和管理暂 行办法 $>$ 的通知》

2001 《关于建立健全农 村土地经营权流转机 制, 加强土地流转管理 工作的通知》

1992《关于禁止采挖甘 草有关问题的通知》

1992《关于禁止采挖甘 草有关问题的通知》

2012 《关于印发<盐池 中部现代草畜产业示 范带规划 > 的通知》

1984《关于对马尔庄乡 组织乡村干部外出学 习种草种树先进经验 的请示的批复》

从第 0 期开始, $\varepsilon_{1}$ 变动一个单位, $y_{1 t}$ 系列数值的变化解释为 $y_{1}$ 受到自身一个脉冲冲击下的响应函数, $y_{2 t}$ 系列数值的变化解释为 $y_{2}$ 受到 $y_{1}$ 一个脉冲冲击下的响应函数。方差分解结果分别指 $y_{1}$ 受到自身一个脉冲冲 
击后的多期累计影响和 $y_{2}$ 受到 $y_{1}$ 一个脉冲冲击后的多期累计影响。由此,构建以政策工具变量和农户行为 变量作为内生变量的 VAR 模型,可以研究在不同政策工具冲击下农户行为的响应程度差异以及不同政策工 具对农户行为调整的多年累计影响。

3.2.2 原始数据序列的标准化与模型平稳性检验

为了消除变量的异方差性, 避免伪回归, 本文先采用 Z-Score 标准化方法处理原始数据, 公式为 $X^{\prime}{ }_{i}=$ $\frac{\left(X_{i}-\overline{X_{i}}\right)}{\sigma}, X_{i}^{\prime}$ 为标准化后的值, $\overline{X_{i}}$ 为平均值, $\sigma$ 为原始数据序列的标准差。利用 EViews 软件完成时间序列 数据平稳性检验和建模工作。ADF 平稳性检验结果如表 3 所示, 其中, 人均牲畜数量 $P=0.3440$, 接受原假设, 说明原序列是一个非平稳序列, 经过一阶差分后进行单位根检验, $P=0.0000$, 拒绝原假设, 因此, 人均牲畜数 量是一阶单整序列。在建立政策工具对养殖行为影响的 VAR 模型时, 考虑用一阶差分序列建模。人均播种 面积和人均造林面积序列均通过 ADF 平稳性检验, 用原始时间序列建模。通过 LogL、LR、FPE、AIC、SC 及 HQ 等标准比较, 确定最优滞后期数为 1 。模型平稳性检验结果如图 3 所示, 所有单位根都位于圆内, 说明所建 VAR 模型平稳有效,后续的脉冲响应与方差分解结果可靠。

表 3 标准化序列平稳性检验结果

Table 3 Stationarity test results of standardized series

\begin{tabular}{lccccc}
\hline $\begin{array}{l}\text { 变量 } \\
\text { Variable }\end{array}$ & $\begin{array}{c}\text { 检验形式 Test method } \\
(C, T, K)\end{array}$ & $\begin{array}{l}T \text {-统计值 } \\
T \text {-statistic }\end{array}$ & $\begin{array}{c}\text { 临界值 } \\
\text { Critical value }\end{array}$ & $P$ & $\begin{array}{c}\text { 结论 } \\
\text { Conclusion }\end{array}$ \\
\hline CA & $(0,0,1)$ & -3.35 & $-1.95(5 \%)$ & 0.0014 & 平稳 \\
LN & $(0,0,0)$ & -0.84 & $-1.95(5 \%)$ & 0.3440 & 非平稳 \\
DLN & $(0,0,0)$ & -6.31 & $-2.63(1 \%)$ & 0.0000 & 平稳 \\
FA & $(0,0,1)$ & -3.03 & $-2.63(1 \%)$ & 0.0036 & 平稳 \\
RE & $(0,0,0)$ & -3.93 & $-2.63(1 \%)$ & 0.0003 & 平稳 \\
GS & $(0,0,0)$ & -4.29 & $-2.63(1 \%)$ & 0.0001 & 平稳 \\
SE & $(0,0,1)$ & -2.49 & $-1.95(5 \%)$ & 0.0145 & 平稳 \\
IP & $(0,0,0)$ & -3.60 & $-2.63(1 \%)$ & 0.0007 & 平稳 \\
SR & $(0,0,0)$ & -4.45 & $-2.63(1 \%)$ & 0.0001 & 平稳 \\
PR & $(0,0,0)$ & -5.03 & $-2.63(1 \%)$ & 0.0000 & 平稳 \\
TR & $(0,0,0)$ & -4.87 & $-2.63(1 \%)$ & 0.0000 & 平稳 \\
FC & $(0,0,0)$ & -4.09 & $-2.63(1 \%)$ & 0.0002 & 平稳 \\
MA & $(0,0,0)$ & -3.78 & $-1.95(1 \%)$ & 0.0004 & 平稳 \\
\hline
\end{tabular}

$\mathrm{CA}$ : 人均播种面积 Cultivated area per capita; LN : 人均牲畜数量 Livestock number per capita; DLN: 一阶差分后的人均牲畜数量 Livestock number per capita by first difference;FA: 人均造林面积 Forestland area per capita;GS: 直接提供 Government service; RE: 规制 Regulation; SE: 国有企 业 State-owned enterprise;IP: 信息与劝诫 Information and persuasion;PR:使用权 Property right; SR:补贴和奖励 Subsidy and reward;TR:税收和使用 费 Tax and royalty; FC: 家庭和社区 Family and community; MA:市场 Market; $C, T, K$ 分别表示常数项、时间趋势和滞后阶数,滞后阶数由 SIC 准则 确定

\section{4 结果与分析}

\section{1 农户行为对政策工具冲击的响应}

脉冲响应函数反映了人均耕作面积、人均牲畜数量、人均造林面积在受到自身和政策工具冲击下的响应 程度。为了突出政策工具的一个标准误差项的冲击对农户耕作、牲畜养殖和造林行为的动态影响,这里只列 出了各项政策工具的脉冲响应函数。如图 4 所示, 横轴表示滞后期数, 纵轴表示响应程度, 负值表示抑制作 用,正值表示促进作用。建模后发现冲击多在第 10 期接近于零,为了对比明显,绘出 10 年的脉冲函数图。总 体上看, 政策工具对农户行为的冲击力度较小, 响应范围在 0-0.30 之间。说明除了政策工具之外,农户行为 更多受自身条件影响。各项政策工具的冲击在 2 或 3 期达到峰值之后逐渐下降,并在第 10 期左右趋近于 0 , 
CA-MAN

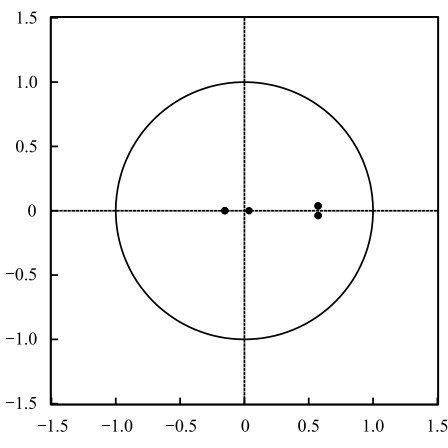

DLN-MAN
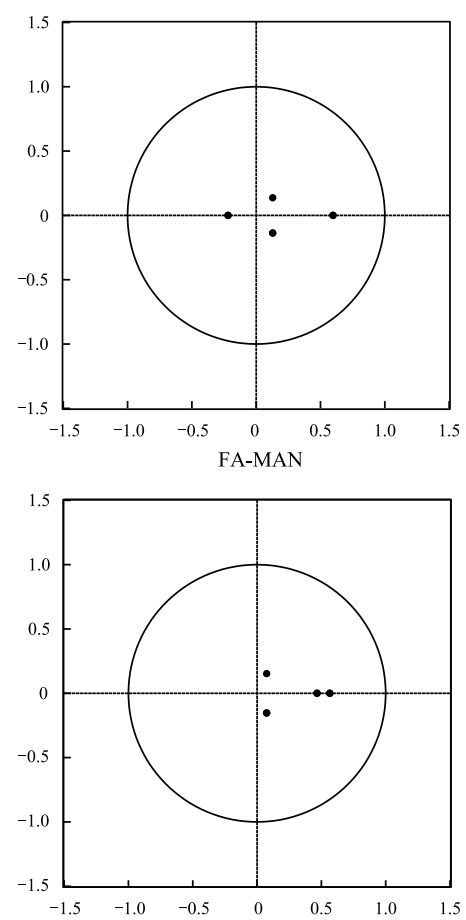

CA-HYB

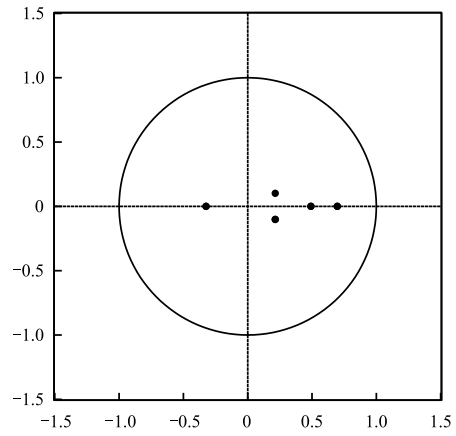

DLN-HYB
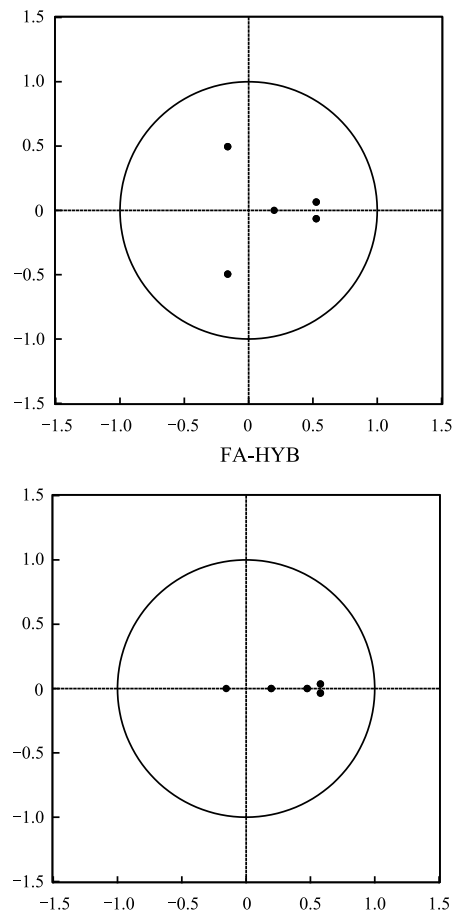

CA-VOL

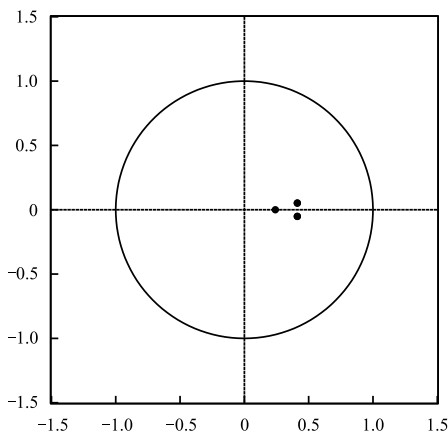

DLN-VOL
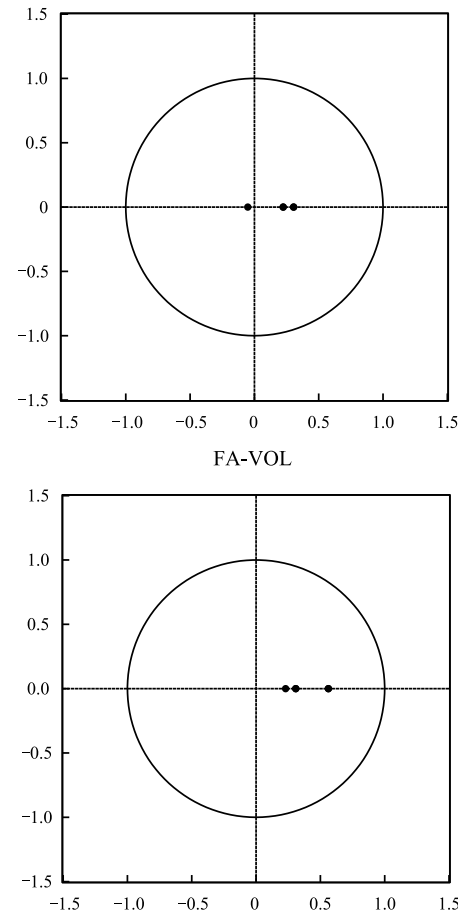

图 3 VAR 模型检验结果

Fig.3 Test results of VAR model

MAN : 强制型政策工具 Mandatory instrument; HYB : 混合型政策工具 Hybrid instrument; VOL: 自愿型政策工具 Voluntary instrument。CA-MAN 表示耕作行为与三种强制型工具建立的 VAR 模型, 其它同理

表明政策工具对农户行为具有较强的短期影响,后期影响逐渐减弱,持续时间为 10 年左右。直接提供工具对 人均播种面积和牲畜数量都具有较明显的积极影响,分别为 0.29 和 0.28 , 规制工具对人均造林面积具有明显 的正面冲击,为 0.19 。总体上看,强制型工具对耕作、牲畜养殖和造林行为的影响最大。

4.1.1 农户耕作行为对政策工具的响应

盐池县位于农户交错区,当地的主要作物为玉米、养麦、糜子等。从图 4 可以看出,十种政策工具对农户 耕作行为都有一定影响, 影响最大的依次是直接提供 $(0.30)$ 、国有企业 $(-0.18)$ 、税收和使用费 $(-0.14)$ 、使用 权 $(0.12)$ 。具体来看, 规制和直接提供、产权和补奖工具的一个标准差冲击对人均耕作面积产生了正向影响, 这表明政府的直接引导,如建立专业的领导小组、派科技人员下乡等行为对农户的耕作行为产生了较大促进 作用。规制工具的影响体现在禁牧后舍饲成本上升,导致部分农户扩大玉米等作物的种植面积,自产自销,降 低养殖成本。另外, 土地利用价值上升, 部分农户选择种植苏丹草等优质饲草出售。路慧玲、陈洁等 ${ }^{[19,37]}$ 在 对盐池县进行实地调查中也发现类似情况。另外, 政府大力调整种植结构, 扶持小杂粮产业发展, 加大对糜 

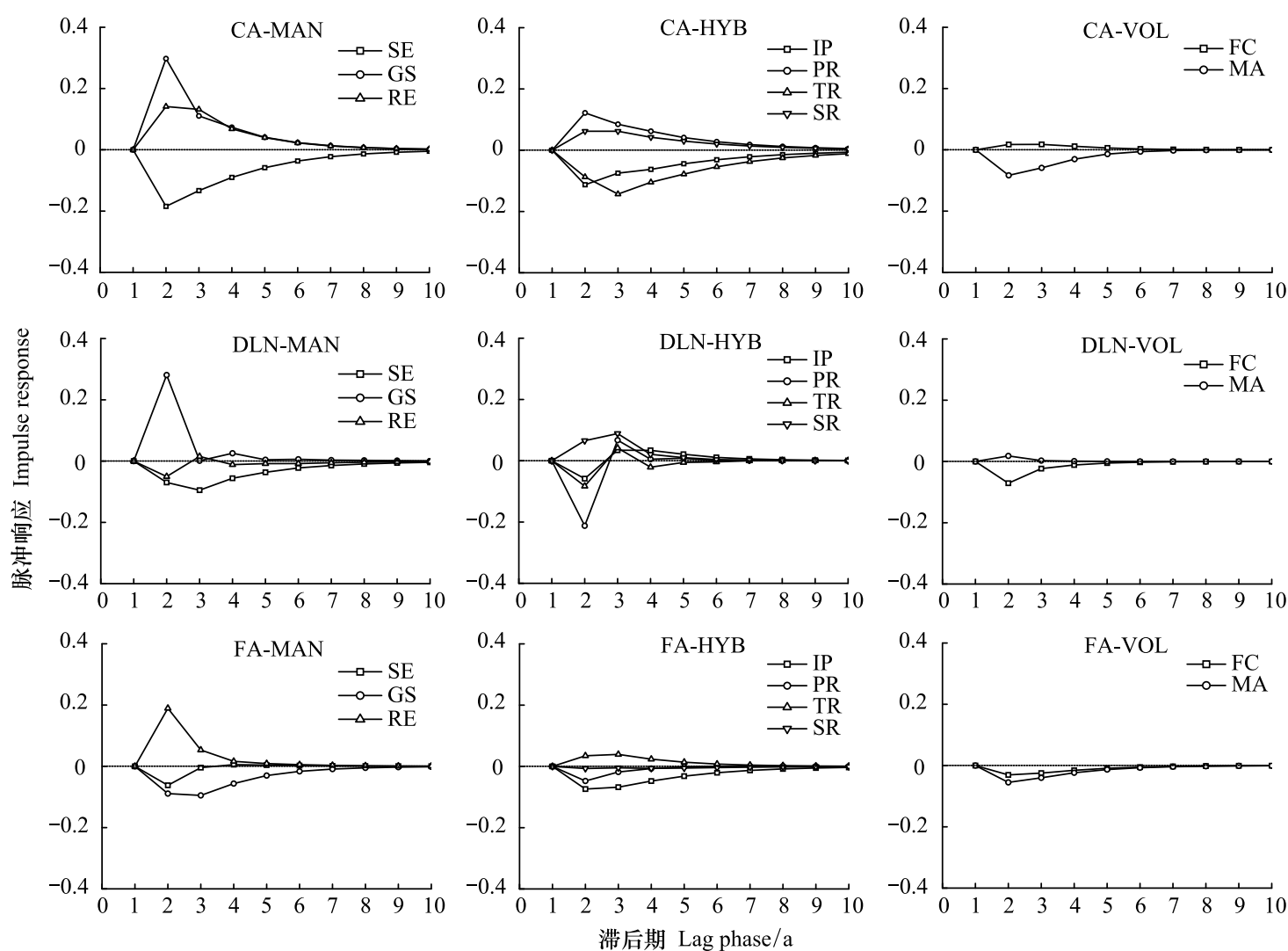

图 4 人均播种面积、牲畜数量、造林面积对政策工具的响应

Fig.4 Response of per capita cultivated area, livestock number and afforestation area to policy instruments

$\mathrm{CA}$ : 人均播种面积; $\mathrm{LN}$ : 人均牲畜数量; DLN:一阶差分后的人均牲畜数量; FA : 人均造林面积; GS: 直接提供; RE: 规制; SE: 国有企业; IP: 信 息与劝诫; $\mathrm{PR}$ : 使用权; $\mathrm{SR}$ : 补贴和奖励; $\mathrm{TR}$ : 税收和使用费; FC: 家庭和社区; $\mathrm{MA}$ : 市场

子、菾麦等经济作物的补贴,这促使更多农户重新开垦以前撂荒的土地,以获得更多的经济补偿。信息与劝 诫、税收与使用费和市场工具的使用有助于缩小播种面积, 税收和使用费工具的影响要稍滞后于其它两项工 具。税收和使用费工具的负面作用在于,在取缔农业税以前,农户需要按照耕地面积缴税,为了少缴税款,农 户会采取瞒报实际耕地面积的做法, 从而导致面积减少。市场工具的负面效果可能在于农户为了获得更高的 收益外出打工, 放弃耕作。田玉军等 ${ }^{[38]}$ 的研究结果也认为务农机会成本促使农户在农业种植和外出务工之 间做出选择和优化资源配置。

4.1.2 农户放牧行为对政策工具的响应

从人均牲畜数量对政策工具的脉冲响应函数图看出, 政策工具的冲击在 $2-3$ 达到最大值, 且部分工具的 冲击存在正负波动。畜牧业是盐池县的支柱产业,政策对畜牧业的影响很大。在新政策出台后,农户会产生 相应的应激策略,并在之后的长时期内逐渐调整, 以达到利益最大化。如禁牧之初, 由于政府加大监督和罚款 力度,农户的主要应激策略是减少牲畜数量; 而在之后与政府的博亦中, 农户的养殖行为开始分化, 有的彻底 放弃养殖, 有的半舍饲半偷牧, 另外还有部分农户完全圈养, 成为专业养殖户, 全县的养殖数量反而增加。

在强制型政策工具中, 规制和国有企业对人均牲畜数量在第 2-3 年内具有负向影响, 说明这两项工具在 使用后对控制牲畜数量起到了积极作用。直接提供工具在初期具有较强的正向效应,说明政府在牲畜养殖上 的直接参与,如牲畜防疫、品种改良等行为对牲畜数量的增加起了促进作用。在混合型政策工具中,信息与劝 诫工具、使用权和税收和使用费在前 3 年具有负面影响,但之后存在正负波动, 说明三类工具的影响不稳定。 补贴工具具有正面冲击, 可能是由于政府在后续滩羊产业发展中的大量补贴, 如圈棚、饲料等, 刺激部分农户 
扩大了养殖规模。在自愿型工具中,市场工具具有轻微的正面冲击,而家庭和社区工具具有持续的负面影响。

\subsection{3 农户造林行为对政策工具的响应}

在县域层面,每年的造林任务是由退耕还林、保护区建设等多个项目配套实施的,农户作为基层参与者, 负责实际的造林工作。从政策工具对造林行为的冲击来看,规制工具在第二年对人均造林面积有较强的正向 冲击, 为 0.19 , 而除税收和使用费以外的各项工具均是负面冲击, 说明造林行为更多是在政府的主导下进行, 除规制之外,其他工具对造林面积都没有积极影响。在 1981 年出台的《盐池县农业建设总体规划》中,计划 从 83 年开始每年种树约 $6666.67 \mathrm{hm}^{2}$, 在本世纪末种树达到 15.4 万 $\mathrm{hm}^{2}$, 包括机械化林场植树 3.27 万 $\mathrm{hm}^{2}$, 覆 盖率达到 $21.9 \%$ 。由此看出,造林数量实际与政府规划密切相关,模型结果与实际情况比较符合。

\section{2 政策工具对农户行为影响的方差分解}

用方差分解来判断不同政策工具对农户行为变化的累计贡献。表 4 中统计了当滞后 10 期时,政策工具 对农户生计行为的累积解释百分比。从表中数据得出,农户行为变量受到政策工具的累计影响较小,这是因 为农户行为除了受到政策影响之外,也受到气候、家庭变迁、个人健康、地区发展等多种因素影响。在这篇文 章中,主要分析政策工具的影响差异。对于耕作行为,按方差贡献大小依次排列为强制型 $(18.1 \%)>$ 混合型 $(9.51 \%)>$ 自愿型 $(1.06 \%)$, 其中, 直接提供工具的累计影响最大 $(9.00 \%)$; 对于放牧行为, 依次为强制型 $(36.92 \%)>$ 混合型 $(26.75 \%)>$ 自愿型 $(2.30 \%)$, 规制工具和使用权两种工具的影响最大, 贡献百分比分别为 $26.92 \% 、 17.05 \%$; 对于造林行为,依次为强制型 $(5.40 \%)>$ 混合型 $(1.65 \%)>$ 自愿型 $(0.63 \%)$, 其中,规制工具的 影响最大,为 $3.28 \%$ 。由此可以看出,强制型政策工具仍然在调节农户行为中发挥主要作用,混合型工具的作 用稍弱, 自愿型工具的作用最弱。另外, 就 3 种行为受到的冲击力度来看,放牧行为受到政策工具的刺激作用 最强,耕作行为次之,造林行为受到的影响最小。

表 4 方差分解结果/\%

Table 4 Results of variance decomposition

\begin{tabular}{|c|c|c|c|c|c|c|c|c|c|c|c|c|}
\hline \multirow[b]{2}{*}{$\begin{array}{l}\text { 行为 } \\
\text { Behavior }\end{array}$} & \multicolumn{4}{|c|}{ 强制型 MAN } & \multicolumn{5}{|c|}{ 混合型 HYB } & \multicolumn{3}{|c|}{ 自愿型 VOL } \\
\hline & $\begin{array}{c}\text { 国有企业 } \\
\text { SE }\end{array}$ & $\begin{array}{c}\text { 直接提供 } \\
\text { GS }\end{array}$ & $\begin{array}{c}\text { 规制 } \\
\mathrm{RE}\end{array}$ & $\begin{array}{c}\text { 合计 } \\
\text { summation }\end{array}$ & $\begin{array}{c}\text { 信息与 } \\
\text { 劝诫 } \\
\text { IP }\end{array}$ & $\begin{array}{c}\text { 使用权 } \\
\text { PR }\end{array}$ & $\begin{array}{c}\text { 税收和 } \\
\text { 使用费 } \\
\text { TR }\end{array}$ & $\begin{array}{c}\text { 补贴和 } \\
\text { 奖励 } \\
\text { SR }\end{array}$ & $\begin{array}{c}\text { 合计 } \\
\text { summation }\end{array}$ & $\begin{array}{c}\text { 家庭和社区 } \\
\text { FC }\end{array}$ & $\begin{array}{l}\text { 市场 } \\
\text { MA }\end{array}$ & $\begin{array}{c}\text { 合计 } \\
\text { summation }\end{array}$ \\
\hline 耕作 CA & 5.42 & 9.00 & 3.67 & 18.1 & 2.12 & 2.36 & 4.12 & 0.91 & 9.51 & 0.07 & 0.99 & 1.06 \\
\hline 放牧 DLN & 6.93 & 3.07 & 26.92 & 36.92 & 2.19 & 17.05 & 3.12 & 4.38 & 26.75 & 0.25 & 0.25 & 2.30 \\
\hline 造林 FA & 0.33 & 1.80 & 3.28 & 5.40 & 1.14 & 0.21 & 0.29 & 0.01 & 1.65 & 0.17 & 0.47 & 0.63 \\
\hline
\end{tabular}

\section{5 讨论}

通过对上述结果的分析发现,总体上农户 3 种行为对政策工具的响应不是特别强烈,相对来看,放牧行为 受到的影响最大, 且 2-3 年内效应最强。以往研究表明,农户与地方政府之间存在双重博亦结构 ${ }^{[39]}$, 农户在 面对政府要求时会根据自身情况选择相应的适应性策略。这种应对模式正好解释了政策的短期效应,且作为 主要生计的放牧活动会受到最大影响。如盐池县实施退牧还草政策后, 由于草地的利用受到限制, 农户会考 虑缩减养殖规模和扩大粮食作物种植面积等 ${ }^{[19]}$, 随后生计方式日益分化, 非农化现象突出, 收人结构趋于多 元化 ${ }^{[40]}$ 。就此次研究结果来看, 政策工具对农户行为的影响程度不太强烈, 说明农户行为模式的转变并非只 受单一工具影响,工具的组合、外部环境以及农户自身资源禀赋等多种因素可能对农户行为产生更大影响。 如安神玮等曾做过研究,证明农户养殖业收人提高并非完全是“退牧还草”生态政策的影响,而是结合社会经 济发展、粮食价格变化、思想观念转变和通货膨胀等多种因素的结果 ${ }^{[41]}$ 。从农户视角来看,出于个人利益最 大化目标,农户做出有利于生态保护行为的意愿受到自身生计资本以及政策感知的双重影响, 如自然资本会 产生负面影响,而金融资本和人力资本会产生正向影响 ${ }^{[42]}$ 。

这篇文章利用大量一手资料,以盐池县为例,对不同政策工具的作用进行了实证研究。从 VAR 模型结果 
来看, 各项工具对农户行为的影响具有程度和方向上的差异。但总体来看,虽然研究结果可以用于各项工具 作用的初步对比,但是由于原始数据仅选取频度代表工具变量, 因此结果可能并不能完全说明工具的效力。 在前期工作中, 我们发现政府偏好强制型工具, 随着社会的发展, 手段愈发多元, 补贴和奖励、市场等工具的占 比逐渐增加 ${ }^{[35]}$ 。这实际上反映了命令控制类工具在我国科层制管理体制中的运用范围广, 可操作性强。从 研究结果看, 强制型工具如直接提供和规制的作用要明显高于其他工具。这一方面是由于违反这类工具的代 价相对较大,在博亦中农户倾向于服从; 另一方面也可能是传统管理思想在一定程度上影响了民众和政府对 自身角色的认知，政府被默认为公共事务的承担者，民众循规办事。这些进一步巩固和发展了直接提供、规制 等传统工具的优势。然而,市场等自愿型工具的作用比较薄弱,但这可能是由于这些工具可以自发而非由政 府引导, 政府运用较少, 从频度上不能完全体现工具的实际参与度。因此,这些自愿型工具的作用也许不能完 全被模型所展示的结果说明。实际上,在一个完整的自然-社会-经济系统中,农户在经济系统中的角色强烈 影响了农户的资源配置行为,农户的日常经济活动以及由此导致的资源利用行为是连接政策与生态质量的桥 梁。随着外部市场的形成和开放,农户参与市场活动的形式多样化,生计方式多样化,进而导致自然资源利用 方式的多样化。

从政策制定到农户决策到产生效应的每个环节都会影响到一项政策最终的实施效果。政策工具实质上 是通过限定作用对象和行为模式, 调节人的活动范围以及资源配置方式。在生态治理领域, 以往关于政策或 政策工具作用的研究,常将其作为一个背景看待,基本不涉及政策本身的特征。主要有几种方式,一是以政策 实施节点为基准, 通过遥感手段直接调查生态质量的时空变化; 二是直接在措施层面, 研究比如围栏封育、休 牧等多种条件组合对草地恢复的影响; 三是考察对农户行为的影响,研究农户对某一项政策的感知和行为调 整模式, 并延伸讨论生态治理效果; 四是将政策的有无作为模型的一个解释变量代人模型建模。然而, 要优化 决策体系,提高施政水平,除了关注结果,对政策本身的关注也不可忽视。目前的研究认为,政策工具的选取 也并非是政策效力的决定性因素, 政策组合、政策网络、政策系统等也对政策效果产生重要影响。工具属性作 为政策研究系统中的一部分, 从工具视角进行研究仅是政策优化的一个开始。面对日益繁复的公共事务和复 杂的决策环境, 还需要以政策工具为突破口, 加大对生态治理政策工具的研究, 促进政策工具理论的本土化改 造和利用。

此次研究还存在以下几点需要进一步完善,一是研究结果虽然可以初步判断各项工具的正负影响,但任 一政策工具都可能产生双向影响。因此, 还需要就具体问题, 加强政策工具混合效应研究, 深人分析各项工具 之间的协调性和互补性; 二是我们只强调了政策的工具属性,但深人的政策分析还应考虑政策目标合理性、执 行效率、价值等多方面的内容。三是此次研究利用了工具的初步量化结果,但一项政策的生成往往遵循政策 惯性, 内容和结构相似度很高, 某一项特殊工具可能是政策文本中的关键, 在编码时不能突出其作用。且同一 种工具的力度也有区别, 比如不同的补占金额。因此,还需要进一步研究如何定量评价政策工具的效用, 如张 振华用政策属性力度、政策目标力度和政策工具力度的乘积表示政策工具效力 ${ }^{[43]}$ 。四是此次选择了播种面 积和牲畜数量作为农户行为指标, 但在调研中发现, 牲畜数量增加可能导致局部土地退化, 总体来讲, 由于养 殖方式改为专业化饲喂, 牲畜数量虽然大幅增长, 但对生态的破坏远不如 80 年代。播种面积的大小能影响沙 漠化程度, 但是后续土地的管理和利用方式更是影响生态治理效果的关键。因此, 在深人判断政策工具对生 态治理效果的影响时,有必要充分了解各阶段农户行为模式的转变。

\section{6 结论与建议}

本文以盐池县为例, 利用 VAR 模型中脉冲响应函数和方差分解对不同类型政策工具对农户耕作、放牧和 造林行为的作用过程及作用程度进行了研究。由于基础政策工具在我国政策环境中的通用性,本文的结果对 其他地区的生态治理政策优化也具有一定的参考价值。经分析得出:

1) 不同政策工具对农户各项行为的刺激作用具有方向和程度上的差异。强制型工具在调节农户行为时 
作用最明显,尤其是直接提供和规制两种工具。政策工具的冲击多在 $2-3$ 年达到峰值, 随后效果逐渐减弱, 10 年左右基本消失。据了解,地方某一项政策出台后,一般只在当年实施,随后自动失效,或用新的文件覆 盖。地方每年会根据当地的突出问题,制定新的政策并调整工具的选择。部分政策工具作用时间较长,如耕、 草、林地的三权固定; 而有些政策工具,如直接提供、补贴、市场工具等作用时间稍短。政策的制定和实施是动 态的,政策实施后的影响又反馈于政策制定。根据这一特点,政府每年应及时评估政策效果, 总结经验,并调 整接下来的政策工具选择,实现短期刺激与长期调控的均衡,更好地实现政策目标;

2) 政策工具对农户行为的冲击力度有限,农户更多受到自身条件影响,其中放牧行为受到的冲击力度最 大。结合实地调查结果, 可以发现, 畜牧业是盐池的主要产业,牲畜养殖受到政策的影响较大。农户对政策的 响应往往是综合自身的资源禀赋,基于短期的家庭收益最大化做出的相对最优选择,而不会具体去区分政策 工具之间的区别。因此,政策工具的选择应该与当地农户的生产生活紧密联系起来,关注农户的实际需求,因 势利导,才能更好发挥政策效用;

3）政策工具的协调性、政策之间的协调性和一致性是能否实现目标的关键。比如,许多学者认为补贴工 具对农户行为具有重要影响。但实际情况是,草场补贴的资金与农户的损失相比相差太远,如果没有政府的 强制监督罚款,那么盐池县的禁牧政策将很难实施。因此,工具之间需要相互配合才能达到阶段性的政策效 果。建议充分凸显政府主体角色,进一步巩固强制型工具的作用,同时根据地区发展需要,开发利用混合型和 自愿型工具,进一步完善生态治理政策体系。

\section{参考文献 (References) :}

[1 ] 张成福. 政府治理创新与政府治理的新典范: 中国政府改革 40 年. 国家行政学院学报, 2018, (2) : 33-39，135-135.

[ 2 ] 陈振明. 政府工具研究与政府管理方式改进——论作为公共管理学新分支的政府工具研究的兴起、主题和意义. 中国行政管理, 2004, (6) : $43-48$.

[ 3 ] 莱斯特 - M. 萨拉蒙. 政府工具: 新治理指南. 肖娜, 译. 北京: 北京大学出版社, 2016.

［4］莱斯特 - M. 萨拉蒙, 李婧, 孙迎春. 新政府治理与公共行为的工具: 对中国的启示. 中国行政管理, 2009, (11) : 100- 106.

[ 5 ] Ding G, Deng Y L, Lin S S. A study on the classification of China's provincial carbon emissions trading policy instruments: taking Fujian province as an example. Energy Reports, 2019, 5: 1543-1550.

[ 6 ] Oikonomou V, Jepma C J. A framework on interactions of climate and energy policy instruments. Mitigation \& Adaptation Strategies for Global Change, 2008, 13(2):131-156.

[ 7 ] Zhao Z F, Thomas C W, Cai T T. The evolution of policy instruments for air pollution control in China: a content analysis of policy documents from 1973 to 2016. Environmental management, 2020, 66(6): 953-965.

[ 8 ] Pakizer K, Fischer M, Lieberherr E. Policy instrument mixes for operating modular technology within hybrid water systems. Environmental Science \& Policy, 2020, 105: 120-133.

[ 9 ] Åström S, Yaramenka K, Mawdsley I, Danielsson H, Grennfelt P, Gerner A, Ekvall T, Ahlgren E O. The impact of Swedish $\mathrm{SO}_{2} \mathrm{policy}$ instruments on $\mathrm{SO}_{2}$ emissions 1990-2012. Environmental Science \& Policy, 2017, 77: 32-39.

[10] Hille E, Althammer W, Diederich H. Environmental regulation and innovation in renewable energy technologies: does the policy instrument matter?. Technological Forecasting and Social Change, 2020, 153: 119921.

[11] Hettiarachchi H, Kshourad C. Promoting waste-to-energy : nexus thinking, policy instruments, and implications for the environment//Kumar S, Kumar R, Pandey A, eds. Current Developments in Biotechnology and Bioengineering: Waste Treatment Processes for Energy Generation. Amsterdam: Elsevier, 2019: 163-184.

[12] Sironen S, Primmer E, Leskinen P, Similä J, Punttila P. Context sensitive policy instruments: a multi-criteria decision analysis for safeguarding forest habitats in Southwestern Finland. Land Use Policy, 2020, 92: 104460.

［13］肖建华, 游高端. 生态环境政策工具的发展与选择策略. 理论导刊, 2011, (7): 37-39.

[14] Reynolds J F, Smith D M S, Lambin E F, Turner II B L, Mortimore M, Batterbury S P J, Downing T E, Dowlatabadi H, Fernández R J, Herrick J E, Huber-Sannwald E, Jiang H, Leemans R, Lynam T, Maestre F T, Ayarza M, Walker B. Global desertification: building a science for dryland development. Science, 2007, 316(5826): 847-851.

[15] Howlett M. What is a policy instrument? Tools, mixes, and implementation styles//Howlett M, Eliadis P, Hill M, eds. Designing Government: 
From Instruments to Governance. Montreal: McGill-Queen's University Press, 2005: 31-50.

[16] Howlett M, Rayner J. Design principles for policy mixes: cohesion and coherence in 'New Governance Arrangements'. Policy and Society, 2007, $26(4): 1-18$.

[17] 孙贵艳, 王传胜. 退耕还林(草)工程对农户生计的影响研究一一甘肃秦巴山区为例. 林业经济问题, 2017, 37(5): 54-58.

［18］王丹. 草原生态保护补助奖励政策对牧户非农就业生计的影响 [D]. 兰州：兰州大学, 2018.

[19］路慧玲, 周立华, 陈勇, 马兵, 魏轩. 禁牧政策下宁夏盐池县农户适应策略及其影响因素. 生态学报, 2016, 36( 17) : 5601-5610.

[20] Huang Z H, Fan H Q, Shen L Y, Du X Y. Policy instruments for addressing construction equipment emission- - a research review from a global perspective. Environmental Impact Assessment Review, 2021, 86: 106486.

[21] 冀光楠. 天保工程区集体林管理的政策工具研究 [D ]. 北京: 北京林业大学, 2014

[22] 黄明. 政策工具对农村居民群体低碳能源使用行为的影响研究一一以鄱阳湖生态经济区为例 [D]. 南昌: 江西农业大学, 2019.

[23］黄金梓. 社会风险视域下生态扶贫政策工具及其适用机制优化. 求索, 2019，(3)：111-117.

[24] 童洪志，刘伟. 政策工具对农户秸秆还田技术采纳行为的影响效果分析. 科技管理研究，2018，38(4)：46-53.

[25］张可, 聂阳剑. 水环境政策对农业增长与面源污染影响的实证分析. 统计与决策, 2017, (14): 118-121.

[26] 张卫东, 汪海. 我国环境政策对经济增长与环境污染关系的影响研究. 中国软科学, 2007, (12): 32-38.

[27] 黄清子, 王振振，王立剑. 中国环保产业政策工具的比较分析一一基于 GRA-VAR 模型的实证研究. 资源科学, 2016, 38 (10)： 1988-2000

[28］蔡博峰, 张力小, 宋豫秦. 我国北方农牧交错带人地系统脆弱性刍议. 环境保护, 2002, (11): 22-23, 27-27.

[29] 《中国荒漠化 (土地退化) 防治研究》课题组. 中国荒漠化 (土地退化) 防治研究. 北京: 中国环境科学出版社, 1998 .

[30］程彦培, 陈立, 张琳, 陈江. 盐池县沙漠化土地动态变化影响因素分析. 中国水土保持, 2010, (11): 34-36.

[31] Liu X J, Liu X D, Luo X, Fu H L, Wang M M, Li L Y. Impact of different policy instruments on diffusing energy consumption monitoring technology in public buildings: evidence from $\mathrm{Xi}^{\prime}$ an, China. Journal of Cleaner Production, 2020, 251: 119693.

[32] 张坤民, 温宗国, 彭立颖. 当代中国的环境政策: 形成、特点与评价. 中国人口 ·资源与环境, 2007, 17(2)：1-7.

[33］杨洪刚. 中国环境政策工具的实施效果及其选择研究 $[D]$. 上海: 复旦大学, 2009 .

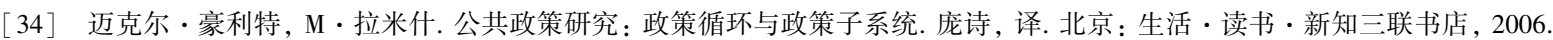

[35］夏翠珍, 廖杰, 郭建军, 刘慧,高扬. 1983-2017 年宁夏盐池县生态治理政策的类型与变化一一基于政策工具视角. 中国沙漠, 2019, 39 (3) : $107-116$

[36] 周蓓. Johansen 协整检验中 DGP 误设的研究与应用 $[\mathrm{D}]$. 武汉: 华中科技大学, 2008 .

[37] 陈洁, 苏永玲. 禁牧对农牧交错带农户生产和生计的影响一一对宁夏盐池县 2 乡 4 村 80 个农户的调查. 农业经济问题, 2008, 29(6)： 73-79.

[38] 田玉军, 李秀彬, 辛良杰, 马国霞, 李占明. 农业劳动力机会成本上升对农地利用的影响一一以宁夏回族自治区为例. 自然资源学报, $2009,24(3): 369-377$.

[39] 陈勇, 王涛, 周立华, 刘宁, 黄珊. 禁牧政策下农户违规放牧行为研究一一宁夏盐池县为例. 干旱区资源与环境, 2014, 28 ( 10)： 31-36.

[40］王一超, 郝海广, 张惠远, 翟瑞雪, 张强. 农牧交错区农户生计分化及其对耕地利用的影响一一以宁夏盐池县为例. 自然资源学报, $2018,33(2): 302-312$.

[41] 安祎玮，周立华，陈勇. 基于倾向得分匹配法分析生态政策对农户收人的影响一一宁夏盐池县“退牧还草”案例研究. 中国沙漠，2016, $36(3)$ : 823-829.

[42] 徐建英, 孔明, 刘新新, 王清. 生计资本对农户再参与退耕还林意愿的影响一以卧龙自然保护区为例. 生态学报, 2017, 37 (18)： 6205-6215.

[43] 张振华, 唐莉, 刘薇. 环境规制科技政策对科技进步与经济增长的影响. 科技进步与对策, 2020, 37(5)：131-140. 